\title{
A teoria queer e a Reinvenção do corpo*
}

\author{
Pedro Paulo Gomes Pereira**
}

A expressão queer, utilizada como forma de auto-designação - repetindo e reiterando vozes homofóbicas que assinalam a abjeção daquele que é denominado queer, mas descontextualizando-as desse universo de enunciação, já que se atribui valores positivos ao termo, transformando-o numa forma orgulhosa de manifestar a diferença -, pode ocasionar uma inversão da cadeia de repetição que confere poder a práticas autoritárias precedentes, uma inversão dessa historicidade constitutiva. (Butler, 2002) Algo novo surgiria, então, desse processo, anunciando a irredutibilidade e expressando a incômoda $e$ inassimilável diferença de corpos e almas que teimam em se fazer presentes.

A utilização de repertório comum de autores, a luta contra a heterossexualidade compulsória (Rich, 1993), a posição contrária a binarismos fáceis, entre outros, são características que conferem uma aura de transgressão e contestação ao pensamento queer, o que às vezes pode sugerir, numa abordagem apressada, uma integração das posições num todo único e compacto. Não é preciso, porém, muito tempo de leitura para se observar as divergências $e$ as diferenças no interior do pensamento queer. Tratar as posições políticas queer de forma unificada, por exemplo, desconsiderando a especificidade de cada pensamento, retira a força das propostas e das idéias. Distante do contexto de enunciação e sem a atenção devida à singularidade de cada

\footnotetext{
" Resenha de A Reinvenção do Corpo: sexualidade e gênero na experiência transexual, de Berenice Bento. Recebida para publicação em setembro de 2006.

*** Professor no Departamento de Ciências Sociais da Universidade Federal de São Paulo - UNIFESP, São Paulo. pedropaulopereira@hotmail.com
} 
A teoria queere a Reinvenção do corpo

corpus teórico, corremos sempre o risco de nublar a densidade das proposições queer - que necessitam de um movimento autoreflexivo intenso e contínuo -, o que conduziria à repetição pura $e$ simples de teorias sem que haja a resistência das realidades analisadas. A teoria se torna, nesse caso, dissociada das realidades empíricas e, sem esse confronto acabamos por entrar num círculo que induz à eterna repetição (periférica) de teorias (centrais). Terminamos, por fim, observando somente aquilo que a teoria nos faz ver, e toda a possibilidade de distorcermos, transgredirmos, estranharmos - ideais eminentemente queer - fica embotada.

Se essas preocupações são justas ou razoáveis, não há como se negar, entretanto, que a atitude contestatória, a posição fora-docentro, o estar à margem, assumidos na própria auto-designação performática, vem conduzindo a uma criativa forma de lidar com as teorias, que se afasta da busca redutora de "aplicar" idéias elaboradas alhures. Em realidade, os principais formuladores da teoria queer conclamam a uma postura autocrítica, a uma atitude crítica que incida sobre o próprio sujeito queer, aludindo-se a hipótese de até mesmo se abandonar o termo, em favor de outro(s) que produza $(\mathrm{m})$ ações políticas mais efetivas. (Butler, 2002:59-60)

É neste contexto que gostaria de ler a obra de Berenice Bento - A Reinvenção do Corpo: sexualidade e gênero na experiência transexual -, publicado recentemente pela Garamond. A postura transgressora de Berenice não se coloca apenas na escolha da transexualidade como "objeto de estudo" - o que conduziria a uma exotização, no sentido pérfido do termo, da experiência transexual -, mas fundamentalmente nas próprias indagações elaboradas. A autora procura verificar os conflitos, as brechas, os interstícios, as fissuras e as disjunções que possibilitam que os sujeitos subvertam as normas de gênero. A inspiração é nitidamente queer. Se as sociedades inventam formas de regular $e$ de materializar o sexo nos sujeitos, e se essas "normas regulatórias" necessitam ser repetidas frequentemente, citadas $e$ reiteradas amiúde, há, contudo, torções e lapsos no processo. Os 
corpos, assim, não se conformam diretamente às regras que os regulam, nunca aderindo completamente às normas que impõem as suas materializações. (Butler, 1999:154) A invenção dos corpos pressupõe, portanto, a sua reinvenção contínua. Berenice procura, então, compreender as performances dos sujeitos que não se conformam em e com seus corpos e como nas práticas cotidianas procuram adequar corpo, sexualidade e gênero, reinventando-os.

A transexualidade foi considerada sempre sob um prisma patologizante, e diversos médicos, psiquiatras, psicólogos, sexólogos, e mesmo cientistas sociais, defenderam que seria uma anormalidade, um desvio que necessita ser corrigido. $\mathrm{O}$ "transexualismo", nesse tipo de raciocínio, assemelhar-se-ia à doença mental. Berenice empreende, então, uma crítica contundente ao discurso biomédico que inventa $\mathrm{o}$ "transexualismo". A autora, por meio das vozes dos próprios transexuais, questiona a legitimidade da biomedicina, demonstrando como esses saberes percebem o "transexual de verdade" como cópia patologizada e mal acabada de seres heterossexuais completos e saudáveis.

$\mathrm{O}$ conjunto de práticas e discursos que atuam sobre os corpos e almas dos transexuais, regulando-os, Berenice denomina de "dispositivo da transexualidade", que pode ser observado na intervenção médica que atua, invariavelmente, no sentido de restabelecer a heterossexualidade supostamente perdida ou ameaçada. A equipe médica opera - o deslize semântico do verbo "operar" é aqui bem apropriado - efetuando a manutenção do dimorfismo dos gêneros, considerado como natural, sempre na busca de afastar as ambigüidades. $\mathrm{O}$ dispositivo da transexualidade é, portanto, heteronormativo.

O fascinante no livro, e a despeito de outros méritos da análise, repousa em como as vozes dos transexuais surgem, traçando elas próprias o desmonte do "transexual de verdade" elaborado pelo pensamento biomédico. A abordagem não subsume as vozes num sofisticado aparelho conceitual; antes, faz dialogar a teoria queer e a experiência transexual. Essa construção 
A teoria queer a Reinvenção do corpo

textual permite que se afaste de certa prática - assinalada no início deste texto - de aplicar a teoria queer em contextos diferenciados, não fazendo dialogar as concepções de pesquisador e pesquisado, procedimento que por si exclui as vozes que se desejava compreender, impondo distância intransponível. E é justamente a busca de eliminação desta distância, numa escuta atenta $e$ perceptiva, bem como a intenção da narrativa de deixar fluir as vozes dos transexuais, construindo um emaranhado que nem a autora controla completamente, aquilo que mais caracteriza a obra de Berenice. Desse emaranhado surgem personagens diversos, não emoldurados pelo desejo de uma narrativa que já sabe antecipadamente e que deve somente alocar os sujeitos em nichos teóricos pré-construídos; personagens como: transexuais masculinos que se declaram gays; transexuais femininos que são lésbicas; transexuais que não querem fazer a cirurgia, mas apenas mudar a identificação nos documentos - ou seja, exigem o reconhecimento do Estado -; transexuais masculinos bissexuais. Os corpos-homem e corpos-mulher parecem perder as amarras biológicas e se reinventam continuamente, fazendo-nos questionar se são adequados realmente os termos homem-mulher, alocados em justaposição ao vocábulo corpo. A experiência transexual, assim, possibilita a autora questionar a vinculação direta de gênero e sexualidade. As vozes dos transexuais surgem no livro sempre demonstrando claramente que a orientação sexual está desvinculada da luta por um corpo que coadune como ideal de gênero.

O que nos conta a experiência transexual? Ela nos diz, afirma Berenice, que a busca pela cirurgia transgenitalização não é a primeira intervenção; outras operações anteriores e inadequadas colocaram os sujeitos que reivindicam a intervenção médica a corrigir as falhas. As normas regulatórias não foram eficazes: o próprio contexto de gênero possibilita a insurgência dos dolorosos conflitos identitários, e os corpos se embatem com as mesmas normas que os engendraram. (cf. Preciado, 2002) 
Ao colocar a radicalidade da experiência transexual como meio de pensar a performatividade dos gêneros, Berenice não constrói os sujeitos transexuais de forma idealizada. Ao contrário, eles surgem nas narrativas com seus medos, receios, qualidades $e$ defeitos. O que se acentua é a capacidade da experiência transexual demonstrar o caráter performático do gênero. Porém, tampouco se assinala qualquer imediatismo no processo, visão que construiria sujeitos que precederiam ao gênero e optariam voluntariamente por assumir uma ou outra forma. (Butler, 2002) Contra essa percepção voluntarista, o transexual aparece em $A$ Reinvenção do Corpo como um efeito de um regime que regula as diferenças de gênero, e como um ponto de conflito dentro da hierarquização coercitiva de gênero. $\mathrm{O}$ que se enfatiza são os conflitos de sujeitos que se sentem deslocados e buscam inteligibilidade dentro da matriz de gênero; essa busca, no entanto, demonstra o caráter de invenção da própria matriz. O transexual não é transformado num herói, nem possui autonomia absoluta das normas de gênero; é somente um sujeito que sofre a experiência conflituosa e dolorosa de se sentir inadequado. ${ }^{1}$

Outras características marcam a obra de Berenice. Em primeiro lugar, a luta por transcender o âmbito exclusivamente disciplinar. Numa época em que as disciplinas, pelo menos no Brasil, parecem erigir barreiras que garantam o poder de decidir sobre o que é válido ou não - $e$, por meio desse julgamento, deliberar sobre bolsas, títulos, vagas nas universidades, verbas para as pesquisas -, buscar quebrar as barreiras disciplinares soa como heresia. Todavia, é esta exatamente uma das características da proposta queer, e é esta a intenção de Berenice. Em segundo lugar, o posicionamento sempre dosado pela investigação e pelo rigor: a autora, por todo o livro, não se exime de se posicionar, de procurar dizer a verdade ao poder - para utilizar aqui uma frase frequentemente utilizada por Edward Said. Por fim, saliento a

1 Ver Butler (2004), principalmente o capítulo "Doing Justice to Someone: Sex Reassignment and Allegories of Transsexuality". 
A teoria queer a Reinvenção do corpo

coragem de tratar direta e claramente questões polêmicas $e$ provocativas.

E como todo texto provocativo, A Reinvenção do corpo deixa lacunas, brechas que forçam leituras variadas, impelindo leitore(a)s a construir suas próprias indagações. Alguns desejariam, por exemplo, uma análise que se detivesse na compreensão de como e de que forma a experiência transexual se vincula ao contexto do individualismo. ${ }^{2}$ Berenice incita-nos a verificar as relações entre a transexualidade $e$ a emergência do sujeito moderno; noutras palavras, a questão se concentraria em compreender a experiência transexual no âmbito da Pessoa moderna. Foi a grande transformação (Polanyi, 2000) que possibilitou a concepção do ser humano como transformável, mutável, em função de uma experiência no mundo sensível. Até que ponto, então, as relações de sexualidade e sensibilidade, na experiência transexual analisada por Berenice, seriam de "perfectibilidade", "experiência" e do "fisicalismo"? - replicando aqui, em contexto diferenciado, as preocupações teóricas que Luis Fernando Dias Duarte (1999:25; 2004:42) tem expressado em diversas ocasiões.

Acompanhando a leitura de Berenice em seu desejo de buscar sempre contextualizar as narrativas dos pesquisados, podemos ainda indagar sobre as dimensões de uma das principais fontes de identidades do mundo moderno, a nação, e seus efeitos na experiência transexual. Berenice pesquisou em diversos locais: Goiânia, Brasília, Valência, Barcelona e Madri. Como se sabe, nações são comunidades imaginadas que se constroem por meio de estratégias discursivas, compostas por imagens, panoramas, cenários, de eventos históricos, e procuram estabelecer uma experiência compartilhada, realçando a idéia de origem comum, de continuidade e de tradição compartida. Evidentemente, as

2 Não podermos, contudo, relacionar exclusivamente o transexual ao universo do individualismo, como se pode observar nos textos do livro organizado por José Antonio Nieto (1998). 
culturas nacionais não são essencialmente unificadas $e$ homogêneas, tratando-se, antes, de um dispositivo discursivo que representa a diferença como unidade ou identidade. ${ }^{3}$ Tendo em vista o contexto analisado por Berenice, fica a pergunta: qual seria a relação entre os transexuais e os dilemas identitários da nação? Ou ainda: A transexualidade seria fenômeno que se desprende da nação? A experiência transexual seria a mesma em Valência e Madri ou em Barcelona e Goiânia? Talvez, sobre esse aspecto, o trabalho de autoras como Glória Anzaldúa possa contribuir para inquirirmos ainda mais sobre os vários vetores da diferença, resultantes dos desequilíbrios e exclusões.

Outras questões. Paul Rabinow (1992) salienta que as mudanças científicas - principalmente as genéticas - vem se impregnando à sociedade de tal forma que podemos prever uma remodelação da vida social maior do que a causada pela revolução na física. Como entender as intervenções cirúrgicas dentro desse novo universo da biossociabilidade? Sobre as biotecnologias, Mariza Corrêa (2004) lembra que as intervenções nas crianças de sexo ambíguo e no corpo dos transexuais devem alertar aos novos parâmetros para as análises nas ciências sociais. Corrêa aborda, por exemplo, a intervenção médica no caso dos transexuais, enfatizando como as sociedades modernas ficam reféns do poder médico, incluindo as cirurgias no âmbito das "mutilações genitais". Como, então, compatibilizar o desejo "mudar de sexo" com os direitos que devem ser garantidos aos sujeitos que reivindicam as "cirurgias reparadoras", sem que as novas formas de biotecnologia assegurem, mais uma vez, a vitalidade do poder médico? De que forma relacionar a experiência transexual às formas de biossociabilidade de que nos fala Rabinow?

Como se nota, são muitas as indagações que o livro de Berenice suscita. Não poderia ser diferente para um tema tão

${ }^{3} \mathrm{O}$ conceito de comunidade imaginada foi elaborado por Benedict Anderson (1989). 
A teoria queere a Reinvenção do corpo

intrigante $e$ atual e para perguntas tão sérias como as que a autora elabora. De qualquer forma que se pense o livro, ou que se venha a analisá-lo no futuro, acredito que será sempre apontada como sua maior contribuição a possibilidade de vozes subalternas, à margem, se apresentarem, desconstruindo as certezas médicas e os estereótipos de grande parte da sociedade; seres que emergem, então, concretamente, questionando nossa forma de organizar o mundo e nossa sensibilidade.

Walt Whitman escreveu certa vez sobre seus poemas: "Camarada! Quem toca neste livro, toca num homem". Whitman estava interessando em romper a distância entre autor e leitor, $e$ seus poemas deveriam expressar diretamente o outro, falando dos problemas que afligem as pessoas comuns. Certamente, a linguagem pregou uma peça no poeta: por suas próprias posições o termo "homem" não faz justiça a sua intenção. Podemos, entretanto, estender a assertiva de Whitman para $A$ reinvenção do corpo, com a devida correção: quem toca neste livro se aproxima de corpos transexuais, travestis, drag queens, drag kings, transgêneros, de corpos que importam. ${ }^{4}$

\section{Referências Bibliográficas}

ANDERSON, Benedict. Nação e Consciência Nacional. São Paulo, Ática, 1989.

BENTO, Berenice. A reinvenção do corpo: sexualidade e gênero na experiência transexual. Rio de Janeiro, Garamond, 2006.

BUTLER, Judith. Cuerpos que importan: sobre los límites materiales y discursivos del "sexo". Buenos Aires, Paidós, 2002a [Versão em espanhol de Boddies that Matter: On the discursive limits of sex. New York, Routledge, 1998.

. Undoing Gender. New York, Routledge, 2004.

4 Referência ao título da tradução para o espanhol do livro de Butler: cuerpos que importan. Como se sabe, o título em inglês, Bodies that matter, faz um trocadilho, indicando, simultaneamente, corpos que se materializam e corpos que obtêm legitimidade. 
Pedro Paulo Gomes Pereira

CORRÊA, Mariza. Convenções Culturais \& Fantasias Corporais. In: PEIXOTO, Fernanda et alii. Antropologia, Histórias, Experiências. Belo Horizonte, Ed. UFMG, 2004.

DUARTE, Luiz Fernando Dias. O império dos sentidos: sensibilidade, sensualidade e sexualidade na cultura ocidental moderna. In: HEILBORN, M. L. (org) Sexualidade. O olhar das ciências sociais. Rio de Janeiro, Zahar, 1999.

A sexualidade nas Ciências Sociais: leitura crítica das convenções. In: PISCITELI, Adriana et alii (orgs.) Sexualidade $e$ Saberes: Convençóes e fronteiras. Rio de Janeiro, Garamond, 2004.

NIETO, José Antonio. Transexualidad, transgenerismo y cultura: antropología, identidad y género. Madrid, Talasa Ediciones, 1998.

PRECIADO, Beatriz. Manifiesto contra-sexual: prácticas subversivas de identidad sexual. Madrid, Pensamiento Opera Prima, 2002.

POLANYI, Karl. A grande transformação. As origens da nossa época. Rio de Janeiro, Campus, 2000.

RABINOW, P. Artificiality and enlightenment: from sociobiology to biosociality. In: CRARY, J. e KWINTER, S. (orgs.) Incorporations. New York, Zone Books, 1992, pp.234-252.

$\mathrm{RICH}$, Adrienne. Compulsory Heterosexuality and Lesbian Existence. In: ABELOVE, H.; BARALE, M.A; HALPERIN, D.M. (orgs.) The Lesbian Studies and Gay Studies. New York, Routledge, 1993. 